\title{
Recent trends in leprosy in a large district of West Bengal, India, revealed by a modified leprosy elimination campaign (MLEC), 1998
}

\author{
M. G. MANDAL*, DIPAK PAL**, V. MAJUMDAR***, \\ P.C. BISWAS***, S. BISWAS*** AND \\ BIBHUTI SAHA $* * *$ \\ *Zonal Leprosy Officer, Midnapore District, West Bengal, India \\ **Department of Community Medicine, NRS Medical College, Calcutta \\ ***Department of Leprology, School of Tropical Medicine, Calcutta, \\ India
}

Accepted for publication 19 January 2000

\begin{abstract}
Summary A Modified Leprosy Elimination Campaign (MLEC) in September 1998 in the District of Midnapore, West Bengal, covered a population of $8 \cdot 1$ million people and detected 8181 new cases. Available data from 7328 cases were studied to observe the trend for leprosy in this area. Data are presented on sex and age distribution, classification and the proportions of multibacillary (MB), paucibacillary (PB) and single skin lesion (SSL) cases discovered in a period of only 8 days. The large numbers of people examined in this district and the high total of new cases revealed are in keeping with experience in other parts of the State and in other parts of India. However, many cases were found in endemic areas and these will receive special attention in a second MLEC, planned for January 2000.
\end{abstract}

\section{Introduction}

Midnapore in West Bengal is the largest populated district of India (about 10 million) situated near The Bay of Bengal at the southern most part of the State. Topographically, it is divided into two halves - an eastern half of fertile alluvial soil and a western half of infertile laterite soil with forest areas. More than 1.5 million tribal people inhabit the western half, along with $0 \cdot 2$ million poor slum dwellers in its urban part, rendering it backward both economically and in literacy levels in comparison to the eastern part (Figure 1).

MDT was started in this district in March 1991 with a caseload of 31,847. On 31 March 1992, the caseload was 32,159. Every year thereafter caseloads showed a substantial decreasing trend (Figure 2) with a caseload of 4663 on 31 March 1998 due to the routine activities of the State members of the National Leprosy Eradication Programme.

It was, however, presumed by sample survey, performed by the Zonal Leprosy Officer,

Correspondence to: M. G. Mandal 

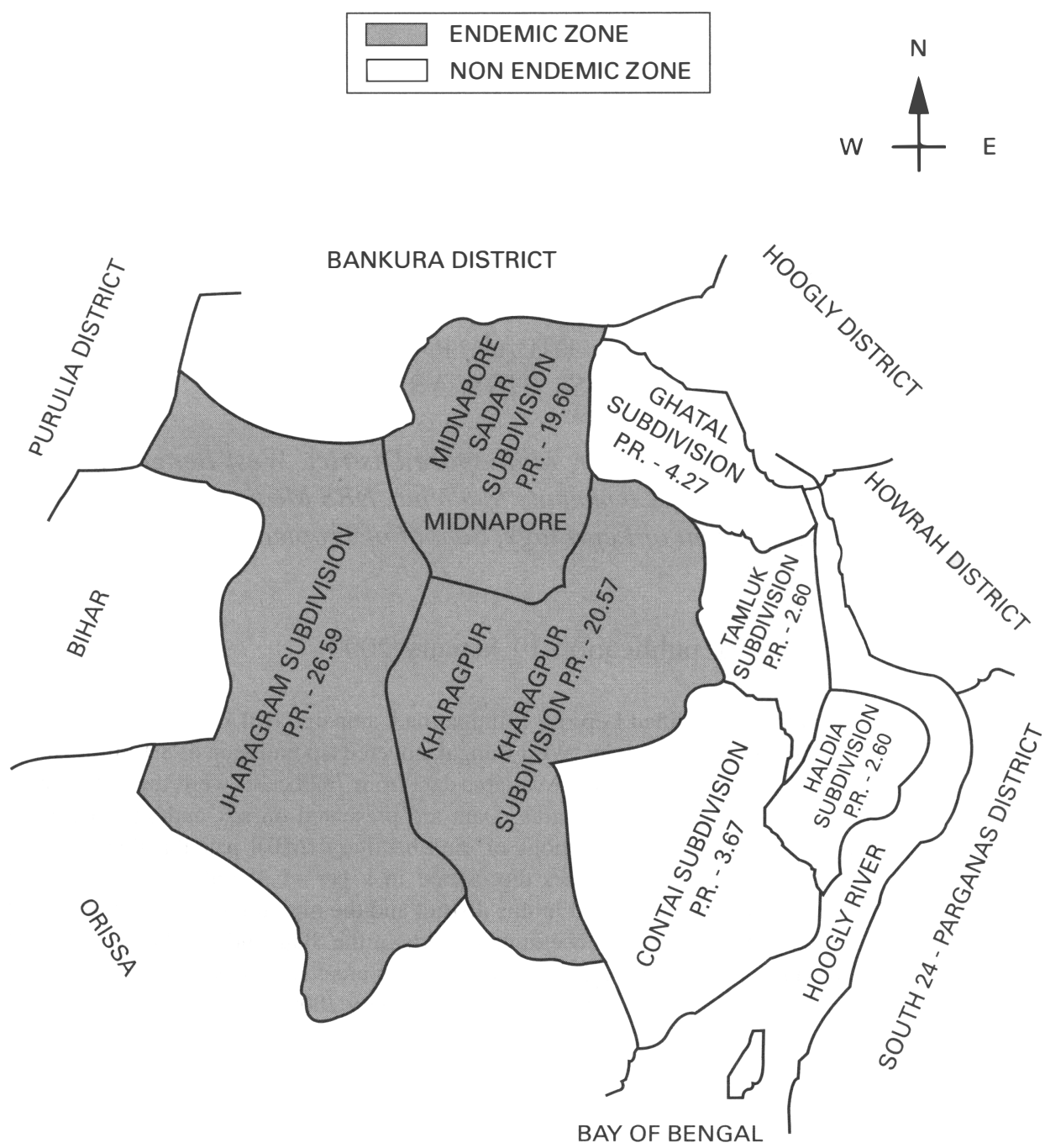

Figure 1. District of Midnapore (popukation approximately 10 million). Case load in September 1998 (after MLEC) was 12,326 .

Midnapore, that the existing case load of 4663 cases represented only the tip of an iceberg of a huge number of hidden cases due to ignorance, illiteracy, social taboos and stigmas. To combat this situation a Modified Leprosy Elimination Campaign (MLEC) was started in this district (and elsewhere in this State) in September 1998.

\section{Materials and methods}

This MLEC included preparatory and active phases. In the initial part of the preparatory phase mass awareness was created by continuous health education, involving all categories of 


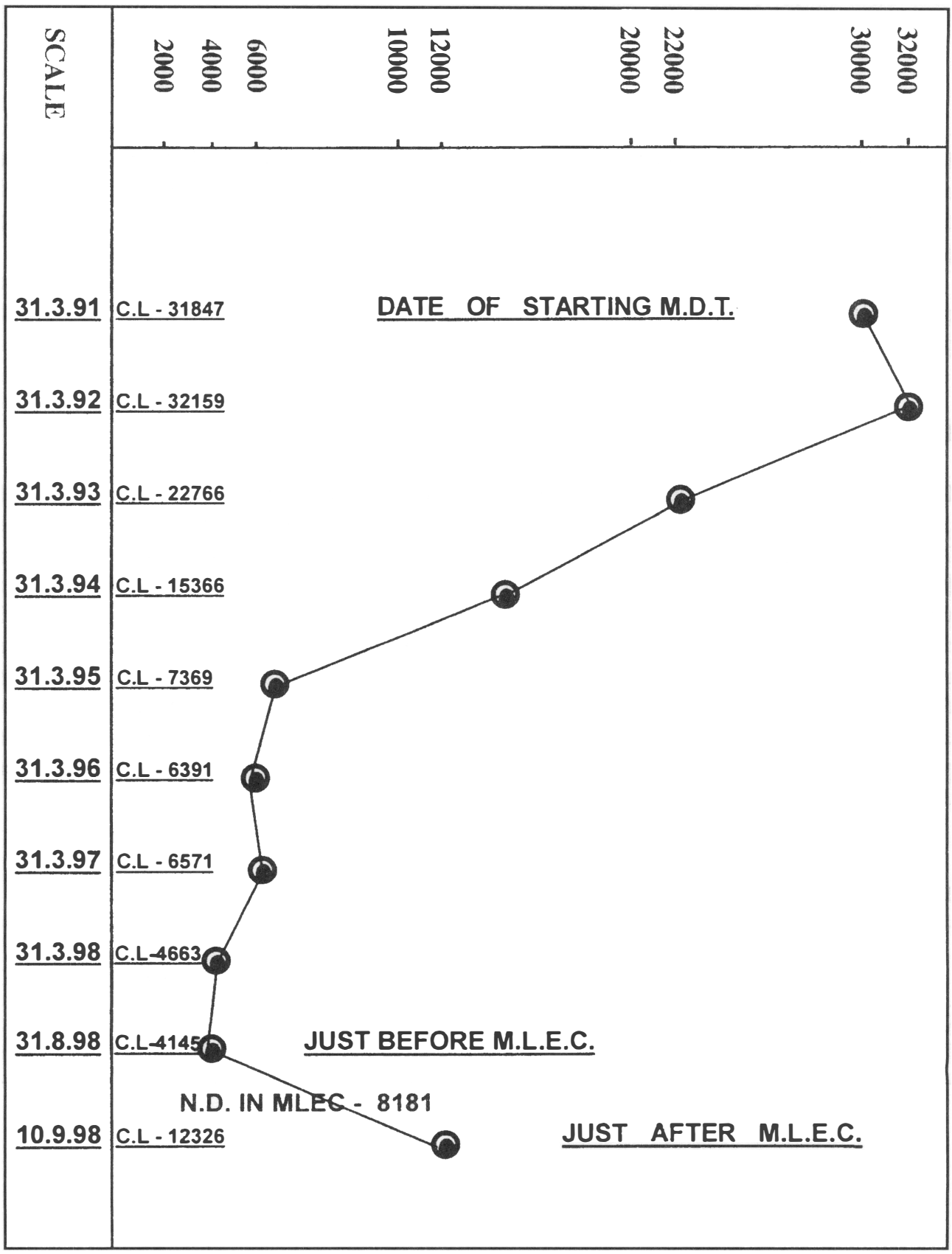

Figure 2. Leprosy picture in Midnapore District from 31 March 1991 to 10 September 1998 (MLEC). C.L. = case load, N.D. = newly detected cases. 
Table 1. Sex distribution of cases

\begin{tabular}{lll}
\hline Male (\%) & Female (\%) & Total \\
\hline $4290(58 \cdot 5)$ & $3038(41 \cdot 5)$ & 7328 \\
\hline
\end{tabular}

health staff. The general population was covered by door-to-door hand-bill distribution, wide audio and audiovisual publicity including TV and radio programmes and publicity in local newspapers. At a later stage, 9500 workers selected for MLEC were trained at 61 blocks and municipalities.

The active phase involved about 3000 teams of survey workers (each consisted of three people) for the enumerated $9 \cdot 2$ million population. The survey examined about $8 \cdot 1$ million people over a period of 8 days (1-8 September 1998).

\section{Results}

In all, 47,854 suspected persons were detected by the survey workers, out of which 8181 cases were confirmed by experienced observers and treated by special teams. Detailed data of 7328 cases were available and analysed for the present study. After MLEC the caseload in this district rose to 12,326 and the prevalence of cases per 10,000 became much higher in the western compared with the eastern part. In the western region, the prevalence rates per 10,000 of the population were $26.59,20.57$ and 19.60 in the three subdivisions, but in the eastern region they were $4 \cdot 26,3 \cdot 67,2 \cdot 60$ and $2 \cdot 60$ in its four subdivisions (Figure 1). On the basis of this finding, the western and eastern region could be designated as 'endemic' and 'nonendemic' areas, respectively. Tables 1-6 show sex and age distribution, classification and the proportions of multibacillary (MB), paucibacillary (PB) and single skin lesion (SSL) cases discovered in the MLEC in this district.

Table 2. Age and sex distribution of cases

\begin{tabular}{|c|c|c|c|c|c|}
\hline \multicolumn{2}{|c|}{$\begin{array}{c}0-5 \text { years }(\%) \\
94(1)\end{array}$} & \multicolumn{2}{|c|}{$\begin{array}{c}6-14 \text { years }(\%) \\
1158(16)\end{array}$} & \multicolumn{2}{|c|}{$\begin{array}{c}>14 \text { years }(\%) \\
6076(83)\end{array}$} \\
\hline Male (\%) & Female (\%) & Male $(\%)$ & Female (\%) & Male (\%) & Female (\%) \\
\hline $54(57 \cdot 4)$ & $40(42 \cdot 6)$ & $618(53 \cdot 4)$ & $540(46 \cdot 6)$ & $3618(59 \cdot 5)$ & $2458(40 \cdot 5)$ \\
\hline
\end{tabular}

Table 3. Classification of cases

\begin{tabular}{lccr}
\hline SSL (\%) & PB (\%) & MB (\%) & Total \\
\hline $193(2 \cdot 67)$ & $4833(65.95)$ & $2302(31 \cdot 45)$ & 7328 \\
\hline
\end{tabular}


Table 4. Age and sex distribution of different case types. $n=$ number of cases

Age group

(years)

Male

Female

\begin{tabular}{|c|c|c|c|c|c|c|}
\hline \multirow{3}{*}{$0-5(n=94)$} & SSL & PB & $\mathrm{MB}$ & SSL & PB & MB \\
\hline & \multicolumn{3}{|c|}{$n=54(57 \cdot 4 \%)$} & \multicolumn{3}{|c|}{$n=40(42 \cdot 6 \%)$} \\
\hline & 8 & 38 & 8 & 2 & 28 & 10 \\
\hline $6-14(n=1158)$ & \multicolumn{3}{|c|}{$n=618(53 \cdot 4 \%)$} & \multicolumn{3}{|c|}{$n=540(46 \cdot 6 \%)$} \\
\hline \multirow{3}{*}{$>14(n=6076)$} & 25 & 467 & 126 & 30 & 417 & 93 \\
\hline & \multicolumn{3}{|c|}{$n=3618(59 \cdot 5 \%)$} & \multicolumn{3}{|c|}{$n=2458(40 \cdot 5 \%)$} \\
\hline & 73 & 2207 & 1338 & 55 & 1676 & 727 \\
\hline
\end{tabular}

Table 5. Age and sex distribution of different case types in endemic (Midnapore Sadar + Kharagpur + Jhargram subdivisions) and non-endemic (Ghatal + Tamluk + Haldia + Contai subdivisions). $n=$ number of cases

\begin{tabular}{|c|c|c|c|c|c|c|c|}
\hline $\begin{array}{l}\text { Age group } \\
\text { (years) }\end{array}$ & \multicolumn{2}{|l|}{ Area } & \multicolumn{2}{|l|}{ Male } & \multirow{2}{*}{$\frac{\text { Female }}{\text { SSL }}$} & \multirow[b]{2}{*}{ PB } & \multirow[b]{2}{*}{$\mathrm{MB}$} \\
\hline \multirow{3}{*}{$0-5$} & \multirow{3}{*}{ Endemic $(n=74)$} & SSL & PB & MB & & & \\
\hline & & & 44 & & & $30(4$ & \\
\hline & & 5 & 34 & 5 & 2 & 20 & 8 \\
\hline & Non-endemic $(n=20)$ & & 10 & & & $10(5$ & \\
\hline & & 3 & 4 & 3 & 0 & 8 & 2 \\
\hline $6-14$ & Endemic $(n=990)$ & & $531(5$ & & & $459(4$ & \\
\hline & & 23 & 399 & 109 & 27 & 356 & 76 \\
\hline & Non-endemic $(n=168)$ & & 87 & & & $81(4$ & \\
\hline & & 2 & 68 & 17 & 3 & 61 & 17 \\
\hline$>14$ & Endemic $(n=5115)$ & & $3002(5$ & & & 2113 & \\
\hline & & 63 & 1862 & 1077 & 45 & 1469 & 599 \\
\hline & Non-endemic $(n=961)$ & & $616(6$ & & & $345(3$ & \\
\hline & & 10 & 345 & 261 & 10 & 207 & 128 \\
\hline
\end{tabular}

\section{Discussion}

The higher incidence of cases in males corresponds to the general trends in leprosy elsewhere, but the relatively larger number of cases among the female population (41.5\%) probably 
Table 6. Proportion of multibacillary (MB) and non-MB (SSL + PB) cases in non-endemic and endemic areas. $n=$ number of cases

\begin{tabular}{lcc}
\hline & \multicolumn{2}{c}{ Area } \\
\cline { 2 - 3 } Type of case & Non-endemic $(n=1149)$ & Endemic $(n=6179)$ \\
\hline MB & $428(37 \cdot 25 \%)$ & $1874(30 \cdot 33 \%)$ \\
Non-MB & $721(62 \cdot 75 \%)$ & $4305(69 \cdot 67 \%)$ \\
\hline
\end{tabular}

$Z=4.5, P<0.01$

reflects successful case-detection and better mass awareness generated in this campaign. The higher incidence of cases among adults (83\%) also corresponds to general trends of leprosy and the higher percentage of PB cases $(65.95 \%)$ is consistent with the findings elsewhere in this geographical area. However, in contrast to the findings of the South Indian studies, the percentage of SSL cases was remarkably low - only $2.6 \%$ of all detected. In females, a higher percentage of cases was found in the 6-14 years age group (46.6\%), compared to that in adult females $(40.5 \%)$ and this may be due to the higher chances of exposure during free mixing in school, greater social freedom and immunological changes associated with puberty. By contrast the percentage of cases in males was higher in adults $(59 \cdot 5 \%)$ than the 6-14 years age group (53.4\%), possibly attributable to occupational reasons and greater mobility in this group.

The higher endemicity in the Western region could probably be attributable to economic handicap and illiteracy prevailing in this region. The percentage of adult female leprosy cases was slightly higher in endemic areas $(41 \%)$ than in non-endemic areas $(36 \%)$. The finding of more male cases in non-endemic areas (64\%) compared to the endemic areas (59\%) corresponds to the general trend in population. The occurrence of a higher proportion of MB cases in non-endemic areas (37.25\%) compared to that in endemic areas $(30 \cdot 33 \%)$ and the reverse situation in SSL and PB groups (62.75\% versus $69.67 \%)$ calls for explanation, possibly being due to environmental or racial factors so far not identified in this area.

The large numbers of people examined in this district and high total of new cases revealed are in keeping with experience in other parts of the State of West Bengal and in other parts of India. However, the occurrence of $84 \%$ of cases in the endemic areas of the district, despite a great deal of work by the specialized 'vertical' teams of the NLEP in previous years clearly calls for attention. Special emphasis to these areas will be given during a planned second MLEC to be started in January 2000. 